Hong-yong Liu, Yi-qi Chen, Yi Yang

\title{
Technology Innovation and Practice of Green Exploitation Projects of Oil and Gas in the Western Sichuan Gas Field
}

\begin{abstract}
The green (environmentally friendly) project of mining oil and gas in the Western Sichuan area is based on the green low-carbon development strategy of the China Petrochemical Corporation, and it commits to form a complete set of technological developments in oil and gas extraction processes. The project focuses on technology innovation in three aspects: reuse of fracturing flow back fluid, reuse of drilling fluid, and configuration of fracturing fluid and drilling fluid by formation water. A series of technology innovations not only realize the green lowcarbon strategy of the enterprise, but also play an important role in lowering cost and improving efficiency. In addition, the technology achieves remarkable social and economic benefits and inspires the ideas for industry technology innovation.
\end{abstract}

Keywords: oil and gas exploitation, green low-carbon, technology innovation, strategic thinking

\section{Introduction}

The oil and gas industry is the important pillar of the national economy, the development of the oil and natural gas mining industry is related to the development of the national economy and security, it is also closely related to people's life (Zhou \& Tang, 2003). According to the national bureau of statistics, in 2011 China's oil and gas industry achieved a sales revenue of $1.2 \times 10^{12} \mathrm{CNY}$, a total profit of $404.4 \times 10^{9} \mathrm{CNY}$ (Chen, Wang, \& Guo, 2009). Oil and gas as the main fuels and raw material account for about $1 / 6$ of the total industrial output value of the country (Han, 2010). Oil and gas development and environmental protection have a close relationship. In the process of oil and gas field exploration and development, a large amount

Manuscript received September 7, 2014; accepted January 19, 2015

Hong-yong Liu (ه), Yi-qi Chen, Yi Yang

School of Civil Engineering and Architecture, Southwest Petroleum University, Chengdu 610500, China

Email: 1hy78512@163.com of waste is produced, thus influencing the environment. When the environment is destroyed, the development of oil and gas companies will also be affected by the corresponding repercussions (Xie, 1993). How to handle these pollutants in an environmental friendly way has always been a problem in the oil industry. Since the 1970s, a number of domestic and foreign research departments have conducted a lot of research to find some efficient drilling waste treatment methods. Some drilling waste disposal methods found: direct landfill, recycling, micro electrolytic method, solid-liquid separation process, chemical curing method, biologic degradation, oxidation and so on (International Finance Corporation \& World Bank Group, 2007; Long, Sun \& He, 2003; Xue, Ma, \& Li, 2008; The US Environmental Protection Agency, 2010; Ying, 1992). However, drilling waste treatment still incurs high cost, poor applied technology, a risk of secondary pollution of the environment, and has only a small capacity (Wang, Zhou, \& Liu, 2001). Many processing technologies are not suitable for low-cost bulk processing. The Western Sichuan gas field has a complex formation structure and a particular lithology (Wu, Wang, \& Zhang, 2001), existing treatment technologies at home and abroad are not suitable for this situation. Aiming at this condition, the South-west Oil and Gas Company has formed a unique system of innovations, which has won a large number of independent intellectual property rights for core technology. It is of great significance to research on the south-west oil and gas field for technological innovation which aims to improve the efficiency of the drilling waste management technology, and then we can promote the technological progress of the oil and gas industry and realize green mining, build a resource-conserving and environment-friendly society $(\mathrm{Du}$, 2005).

\section{A profile of Western Sichuan oil and gas engineering}

Natural gas production from the south-west oil and gas fields has maintained a strong growth momentum. Growth during "the 9th Five-Year Plan" period was $4.2 \times 10^{9} \mathrm{~m}^{3}$; 
during "the 10th Five-Year Plan" period, $8.5 \times 10^{9} \mathrm{~m}^{3}$; and during "the 11th Five-Year Plan" period, $13.1 \times 10^{9} \mathrm{~m}^{3}$. The natural gas production (including shale gas) strived to reach a $10 \times 10^{9} \mathrm{~m}^{3}$ output annually by the end of "the 12 th Five-Year Plan" period, basically generating billions from the gas field (Xu, 2003). During the period of the "11th Five-Year Plan" period, the Western Sichuan gas field was built. There are hundreds of oil and gas production wells, forming a considerable part of the development zone. It has become the most important petrochemical gas production base in China. The Western Sichuan gas field is the most important component of the rapid growth of the south-west oil and gas production, and is the backbone of the "the 12th Five-Year Plan" period.

The Western Sichuan gas field is very rich in oil and gas resources. In recent years exploration and development have been carried out. It has yielded remarkable amount of oil and gas and brought the region economic development. But because of the densely populated Sichuan region with river, ponds, a dense urban distribution, industrial and agricultural development, land is precious. The ecological environment is fragile and sensitive, because of rich groundwater, higher water levels, and farmland irrigation canals (Zhang, 2005), making the oil and gas environment protection problems become prominent.

\section{The oil and gas engineering technology innovation strategic thought in the Western Sichuan region green exploitation}

\subsection{The background of technology innovation}

\subsubsection{Improper drilling waste management}

Drilling production processes will produce large amounts of pollutants, mainly including drilling cuttings, fracturing fluid flowback, gas well output, and water drilling fluid; the impact to the environment is rather large (Zhao \& Wang, 2004). Pollutant treatment is difficult with a high cost. Each procedure to reduce pollution has reached its limit, and this restriction influences production. The South-west oil and gas drilling pollutant discharge and handling capacity are detailed in Table 1. It is difficult to meet emissions targets in treating water. This has significant potential hazards and risks to the environment, and has become a stumbling block to the normal operation of oil and gas fields (Liu, Zhang, \& Zhao, 2005).

\subsubsection{National policy and law requirements}

The eighteenth report put forward to speed up the construction of an ecological civilization system, establishing and perfecting the strict supervision of environmental protection management systems, independent of environmental supervision and administrative law enforcement. It also seeks to perfect the pollutant discharge permit system and implement a control system which allots enterprises a total amount of permitted pollutants. Those violating the compensation system and causing environmental damage shall be investigated for criminal responsibility according to the law. New environmental laws on environmental protection issues related to the judicial interpretation of the consequences of past crimes have changed once acceptable behavior into sin. Both the unit leadership and the collective are legally responsible. The increase of penalties and liabilities for the producer's production behavior form strong constraints, forcing producers to improve their ways of disposal and reduce emissions.

\subsubsection{Awakening of public environmental awareness}

With the development of society, more publicity, and public environmental awareness, the environmental impact by the project is more and more fully known. The ability to understand the risk is becoming stronger and stronger. There is a higher requirement in the handling of the pollutants in engineering.

In the face of the "12th Five-Year Plan" with a greater challenge in production and higher ecological and environmental protection requirements, the South-west Oil and Gas Company has put forward a green mining of oil and gas engineering technology innovation strategy.

\subsection{Technology innovation strategic thinking}

\subsubsection{Demand-pull and technology push}

With the rapid development of the national economy, the amount of oil and gas production has increased rapidly, oil

Table 1

South-west Oil and Gas Drilling Pollutants Table

\begin{tabular}{lcccc}
\hline Serial number & Sources of waste & Discharge per year (ten thousand) & Annual processing capacity(ten thousand) & Processing costs $\left(\mathrm{RMB} / \mathrm{m}^{3}\right)$ \\
\hline 1 & Fracturing fluid & 10 & 10 & 200 \\
flowback & & 27 & 50 \\
2 & Formation water & 40 & 27 & 180 \\
3 & Drilling waste & 27 & & 27 \\
\hline
\end{tabular}


and gas exploration technology continues to improve, and the environmental standards constantly advance. Oil and gas exploitation need technical innovation, reducing waste pollution, and improving the capacity for environmental protection, thus further promoting the use of new technologies and greater development of more advanced technology as demanded by the market.

\subsubsection{Green low-carbon, cost saving and efficiency}

In the oil and gas production process, the use of innovative technologies for recycling drilling waste effectively, and reducing pollutants, not only contribute to the construction of an ecological civilization, but also to saving the sewage treatment fee, reducing production costs, and improving the recovery efficiency.

3.2.3 Adjusting measures to local conditions, keeping pace with the times

In view of the western Sichuan area lithology's complex geological features drilling engineering should be combined with technological innovation regarding these specific features, always paying attention to the forefront of technology innovation in related fields, and actively absorbing experience in the same industry, strengthening independent innovation ability, and adapting to the national related policy adjustment.

\subsubsection{System security, continuous innovation}

A good system is the guarantee of technological innovation. The corporate management needs to set up a sound management system and improve the construction site management, establish a sustainable innovation system based on performance evaluation and innovative talents incentive mechanism, and then we can promote the application of technology results better.

The innovation strategic thought of the South-west Oil and Gas Company in oil and gas drilling technology are shown in Figure 1.

\subsection{Technology innovation implementation strategy}

The South-west Oil and Gas Company's green exploitation of oil and gas engineering technology innovation practices the strategy of "green environmental protection, energy conservation and emissions reduction". They carry out comprehensive integration and system innovation oriented by the enterprise needs and national policy. They focused on strengthening the technology research of fracturing flowback fluid, formation water and drilling waste, and increasing capital investment, encouraging employees to explore innovation, building a complete and reliable environmental protection system, through continuous pilot learning, forming a green efficient sustainable technology innovation system, providing powerful technical support for green oil and gas field development.

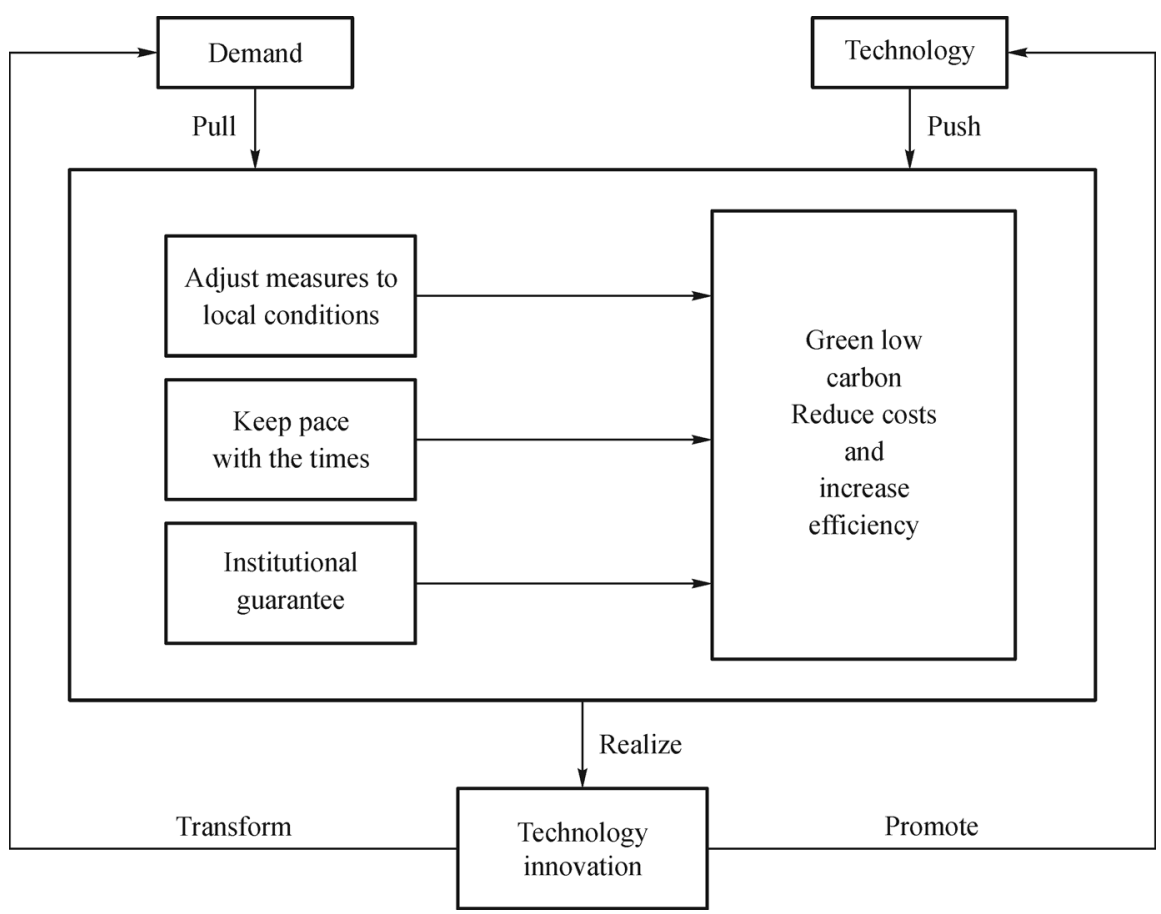

Figure 1. Innovation strategic thought of the South-west Oil and Gas Company in oil and gas drilling technology. 


\section{Technical innovation practice}

\subsection{Fracturing fluid recycle technology}

In 2012, research in fracturing fluid flowback recycling technology was launched, to deal with the core of the fracturing fluid flowback technology, a new type of treatment. Recycling flowback fluid contains a large amount of useful fracturing additives and water, reduces gas pressure, increase environmental protection and reduces the cost of fracturing fluid and liquid waste processing. Aim at the problem such as high processing cost and serious pollution brought by sand fracturing flowback in Western Sichuan region, they first put forward a set of molecular reconstruction based on guanidine gum fracturing fluid flowback reuse technology and have applied for patents. They developed flowback fluid purification treatment technology and at the same time, supported the vehicle-mounted mobile device prizing type processing equipment.

4.2 Fracturing fluid flowback compound drilling fluid technology

After repeated recycling of liquid dispensing fracturing fluid flowback performance degradation (multiple recycling complex fracturing fluid components, performance is not stable, it will effect the fracturing operation), the research work on the configuration of the drilling fluid has been carried out, and realized the zero emissions of the flowback fluid. Primary debugging using fluid flowback is suitable for the back pressure of shallow water in Western Sichuan's drilling fluid formulation.

\subsection{Drilling fluid recycle technology}

In view of the low drilling fluid recycle ratio of Western Sichuan region, they build a real-time drilling scheduling information platform and form a drilling fluid recycling scheduling management system, which improved the drilling fluid repeated utilization ratio by $17 \%$ through the drilling cuttings stripping technology, drilling field management and comprehensive waste treatment, decreased the waste treatment and landfill.

\subsection{Drilling waste reduction technology}

In view of the large amount of drilling waste, with solid waste landfills increasing the environmental risk, measures were taken introducing the well site curing, abandoning well cementing, and strengthening field management, reduced the amount of waste.

\subsection{Formation water fracturing fluid system and technology}

The formation water confecting fracturing fluid work was launched in 2013. They solved the technical difficulties how formation water converted to fracturing fluid by a new type of solubilizer, and formed a complete set of flow processing, created formation water fracturing fluid system, thus opened up a new way for output formation water utilization.

\subsection{Formation water debugging drilling fluid technology}

According to the technical countermeasures of formation water drilling fluid studies, by optimizing the preparation method, the selection resistance main polymer and fluid loss agent, as well as treating agent, the distribution between the basics solved the formation water debugging technical difficulties of drilling fluid preliminary debugging the shallow strata in the Western Sichuan water drilling fluid formulation.

\section{Technical innovation achievements}

Efficient green engineering in the South-west Oil and Gas Company driven by market demand and the technology innovation achieve a good practice effect and a high innovation achievements conversion rate. The effect is remarkable, and the comprehensive result is obvious, and saves costs for the enterprise, achieves good economic returns. Some innovations fill the domestic blank, and have extensive application value. This mainly reflects in:

1) Using fluid flowback $35,000 \mathrm{~m}^{3}$ waste water reuse technology, greatly alleviates the environmental protection question, and ensures normal production. Currently a total of more than 40 wells for fracturing fluid flowback construction have been completed; $72,000 \mathrm{~m}^{3}$ liquid volume has been recycled, a construction success rate of $100 \%$, reducing the use of fracturing additive $164 \mathrm{t}$, which generate direct economic benefits more than 1900 million yuan.

2) Drop flowback reuse water blocking technology achieved a good results. Four wells have been constructed currently recycling a liquid volume of $21,000 \mathrm{~m}^{3}$, a single well has a recycling utilization rate of above $90 \%$, with a construction success rate of $100 \%$.

3) Basically complete shallow strata water fracturing fluid formula indoor debugging. Pilot tests are carried out in two wells, production capacity meets the requirements.

To sum up, the overall benefit amount can recycle or decrease the amount of waste by $434,000 \mathrm{~m}^{3}$ annually, which is $387,000 \mathrm{~m}^{3}$ of waste water, a waste residue of $47,000 \mathrm{~m}^{3}$; estimating the economic benefit at $78.74 \times 10^{6}$ CNY.

\section{Conclusions}

To sum up, technology innovation of the green mining of 
oil and gas engineering does work, not only in energy conservation and environmental protection, but also in savings and efficiency for the enterprise, and achieves remarkable social and economic benefits. Oil and gas technology innovation strategic thought of the South-west Oil and Gas Company has explored a guiding and practical significant path of technological innovation for the oil and gas companies; adjusting measures to local conditions, combining study with actual engineering situations, carrying out scientific research project engineering; keeping pace with the times, understanding advanced technological developments in the industry at home and abroad; Institutional guarantees, establishing and improving the technological innovation incentive mechanisms, improving the system of the construction site management, adherence to the management and technology innovation development side by side. Firm technological innovation strategies, further improve the utilization rate of fracturing fluid flowback, repeat comprehensive scheduling information platform based drilling fluids, and continuous innovation, making the oil and gas field exploitation more ecological and environmental friendly and reap more fruitful social and economic benefits.

\section{References}

Chen, D., Wang, Z., \& Guo, Q. (2009). China's oil and gas sustainable development strategy research. Beijing: Petroleum Industry Press.

Du, Y. (2005). Speed up the development of circular economy to promote resource conservation-oriented society construction. Journal of Tianjin Academy of Social Sciences, 2.

Han, D. (2010). The challenge for the Chinese present situation of oil and gas field development and technology development direction.
Chinese Engineering Science, 5, 51-57.

International Finance Corporation \& World Bank Group. (2007). Environmental, health and safety guidelines for onshore oil and gas development. Retrieved from http://www.ifc.org/wps/wcm/connect/ 4504dd0048855253ab44fb6a6515bb18/Final\%2B-\%2BOnshore\% 2BOil\%2Band\%2BGas\%2BDevelopment.pdf?MOD = AJPERES\&id $=1323153172270$.

Liu, X., Zhang, B., \& Zhao, J. (2005). Oil companies to build up the green management mode. Journal of Oil and Gas Technology, 4, 2.

Long, A., Sun, Y., \& He, Q. (2003). Jilin oil field research. Journal of Drilling Fluid and Completion Fluid, 12, 10-30.

The US Environmental Protection Agency. (2010). Identification and listing of hazardous waste. Retrieved from http://www.epa.gov/ epawaste/hazard/wastetypes/wasteid/pdfs/rcra2614b-ref.pdf.

Wang, R., Zhou, J., \& Liu, G. (2001). Drilling waste management technology. Beijing: Petroleum Industry Press.

Wu, S., Wang, Z., \& Zhang, L. (2001). The western Sichuan foreland basin exploration thought analysis. Oil and Gas Geology, 22, 210216.

Xie, J. (1993). Environmental safety of drilling waste handling methods. Journal of Foreign Oil and Gas Science and Technology, 3.

Xu, H. (2003). Three years at Petro China Southwest Oil and Gas Field Company achievement. Journal of Natural Gas Economy, 2.

Xue, Y., Ma, Y., \& Li, G. (2008). Marine waste drilling fluid treatment study. Journal of Drilling Technology, 4, 19-23.

Ying, N. (1992). Foreign waste drilling fluid treatment technology is introduced. Drilling Fluid and Completion Fluid, 10, 2-5.

Zhang, J. (2005). Western Sichuan oil and gas drilling sewage and waste mud curing processing. Natural Gas Industry, 25, 94-96.

Zhao, X., \& Wang, F. (2004). Waste drilling fluid treatment research progress. Journal of Drilling Fluid and Completion Fluid, 22, 1-5.

Zhou, Z., \& Tang, Y. (2003). From the theory of oil and gas resources in China's future energy development strategy. Journal of Natural Resources, 19. 